\title{
Exploring factors influencing the retention of nurses in a religious hospital in Taiwan: a cross-sectional quantitative study
}

\author{
$\mathrm{Li}^{-H u a} \mathrm{Chiao}^{1 \dagger}{ }^{+}$, Chiu-Feng $\mathrm{Wu}^{2 \dagger}$, I-Shiang Tzeng ${ }^{3+}$, An-Na Teng ${ }^{2}$, Ru-Wen Liao ${ }^{2}$, Li Ying Yu ${ }^{4}$, Chin Min Huang ${ }^{2}$,
} Wei-Han Pan ${ }^{5}$, Chu-Yueh Chen ${ }^{4}$ and Tsai-Tsu Su ${ }^{6^{*}+}$ (I)

\begin{abstract}
Background: Long-term deficits in the nursing labor force and high turnover rates are common in the Taiwanese medical industry. Little research has investigated the psychological factors associated with the retention of nursing staff. However, in practice, religious hospitals often provide nursing staff with education in medicine or the medical humanities to enhance their psychological satisfaction. The objective of this study was to explore factors influencing nursing staff retention in their work in relation to different levels of needs. A further objective was to investigate whether medical humanities education was associated with the retention of nursing staff.
\end{abstract}

Methods: This study used self-administrated questionnaires to survey nurses working in northern areas of Taiwan. The questionnaire design was based on the six levels of Maslow's hierarchy of needs. Participation was voluntary, and the participants signed informed consent documents. Self-administrated questionnaires were distributed to a total of 759 participants, and 729 questionnaires were returned (response rate 96.04\%). Logistic regression analysis was used to estimate the impact of seniority on nurses' reported intention to stay after adjustment for nurse characteristics (gender and age).

Results: In the Pearson correlation analysis, nurses' willingness to stay was moderately correlated with "physical needs", "safety needs", "love and belonging needs", and "esteem needs" $(r=0.559, P<0.001 ; r=0.533, P<0.001 ; r=$ $0.393, P<0.001$; and $r=0.476, P<0.001$, respectively). Furthermore, nurses' willingness to stay was highly correlated with "self-actualization needs", "beyond self-actualization needs" and "medical humanities education-relevant needs" $(r=0.707, P<0.001 ; r=0.728, P<0.001$; and $r=0.678, P<0.001$, respectively). We found that the odds ratios (ORs) of retention of nursing staff with less than 1 year $(\mathrm{OR}=4.511, P=0.002)$ or $1-3$ years $(\mathrm{OR}=3.248, P=0.003)$ of work experience were significantly higher than that of those with 5-10 years of work experience.

(Continued on next page)

\footnotetext{
* Correspondence: tsaitsu@ntu.edu.tw

${ }^{\dagger}$ Li-Hua Chiao, Chiu-Feng Wu, I-Shiang Tzeng and Tsai-Tsu Su contributed

equally to this work.

${ }^{6}$ Graduate Institute of Public Affairs, College of Social Sciences, National

Taiwan University, No. 1, Sec. 4, Roosevelt Road, Taipei 10617, Taiwan

(Republic of China)

Full list of author information is available at the end of the article
}

(c) The Author(s). 2021 Open Access This article is licensed under a Creative Commons Attribution 4.0 International License, which permits use, sharing, adaptation, distribution and reproduction in any medium or format, as long as you give appropriate credit to the original author(s) and the source, provide a link to the Creative Commons licence, and indicate if changes were made. The images or other third party material in this article are included in the article's Creative Commons licence, unless indicated otherwise in a credit line to the material. If material is not included in the article's Creative Commons licence and your intended use is not permitted by statutory regulation or exceeds the permitted use, you will need to obtain permission directly from the copyright holder. To view a copy of this licence, visit http://creativecommons.org/licenses/by/4.0/ The Creative Commons Public Domain Dedication waiver (http://creativecommons.org/publicdomain/zero/1.0/) applies to the data made available in this article, unless otherwise stated in a credit line to the data. 
(Continued from previous page)

Conclusions: With regard to medical humanities education, we recommend adjusting training, as the compulsory activities included in the official programs are inadequate, and adjusting the number of required hours of medical humanities education. Tailoring different educational programs to different groups (especially nurses who have worked 3-5 years or 5-10 years in the case study hospital) might improve acceptance by nursing staff.

Keywords: Nursing staff, Intention to stay, Retention measures, Faith-based hospital, Medical humanities education, Maslow's hierarchy of needs

\section{Background}

Worldwide, there is a deficit of nursing employees [1]. As highly trained and experienced registered practical staff are key personnel in any health care establishment, a sufficient number of these staff is critical to providing patient-centered health services [2, 3]. Previous research has shown a serious deficit of health care employees, especially doctors and nurses, in many countries worldwide [4-6]. In short, the field of nursing is facing a growing deficit of employees in countries around the world, and Taiwan is no exception [7, 8]. Most medical interventions require the services of doctors, nurses, and other health professionals. Research shows that a deficit of health care employees may affect health outcomes such as quality of care, morbidity, and mortality [3-6, 9, 10]. The percentage of practicing nursing staff among all people with a nursing certificate in Taiwan is approximately 59.29\% [11]. Compared to that of Canada (93.6\%) and that of the USA (83.2\%), the percentage of registered practical nurses in Taiwan is obviously low [11]. In addition, nurse turnover rates in Taiwan for 2009-2013 were $16.95,17.12,18.54,19.03$ and $16.45 \%$ [12].

Hospitals in Taiwan can be divided into three categories: medical centers, regional hospitals, and district hospitals. The locations of these types of hospitals in the environment and their building structures, number of beds, facilities, and organizational structures may be similar. However, due to differences in ownership, the management systems and environmental climates of these hospitals may vary. Hospital management systems are likely to differ across different types of hospitals. Management systems affect employees and need to be considered in terms of their job performance and the quality of work life they provide.

Previous research has shown that nursing often faces time-consuming and stressful situations [13]. Factors such as low job control, high job requirements, and deficits in supportive work relationships are associated with stress [14] and high employee turnover in nurses [15]. Research has shown that nurses report their basic needs as being related to employee satisfaction [16], overall health [17], and intention to stay. It is necessary to understand the relationship among basic needs, the quality of work life in health professions, and the intention to remain in these professions. In the study hospital, there is a humanistic culture based on the principle of seeking the ideals of truth, beauty, and goodness. Education in the humanities disciplines provides tangible benefits to the realm of nurses' work [18]. The objective of this study was to explore factors influencing nursing staff retention in their work in relation to different levels of needs. Furthermore, this study aimed to investigate whether medical humanities education was associated with the retention of nursing staff.

\section{Methods \\ Research design and setting}

This was a cross-sectional quantitative study. The study was carried out in Taipei Tzu Chi Hospital. Taipei Tzu Chi Hospital was established in the northern part of Taiwan in 2005, with 1013 beds and a mission to safeguard life and to provide comprehensive medical treatment for all, particularly those with social determinants leading to more challenging access to health services.

\section{Recruitment}

A total of 759 questionnaires (refer to the additional file) were sent to the clinical nursing staff of the Taipei Tzu Chi Hospital. The period of data collection was between May 4, 2017, and April 30, 2018.

\section{Data collection Variables}

The data were collected using a self-report questionnaire consisting of two sections: demographic information and employee satisfaction. The demographic data obtained included gender, age, education level, religion, seniority among nursing staff, seniority among hospital staff, and duration of any medical or human-related education and training received in the past 6 months. Anonymous questionnaires were distributed to clinical nursing staff in the general wards, intensive care wards, and oncology wards but not to staff in outpatient, emergency, and other ward services to ensure work content consistency. 


\section{Measures}

The questionnaire content was discussed with six nursing experts, and the interviewees' (participants') understanding of the vocabulary was measured. The questionnaire content was created based on consensus, and the participants were asked to respond on a five-point Likert scale (ranging from 1 to 5). Three nursing experts conducted expert validity tests according to predefined inspection items such as those assessing whether the items had "clear meaning," were "related to the investigation content," and were "easy to answer." The content validity index (CVI) values of each item were greater than 0.8 . A few items had CVI values less than 0.8 for "easy to answer" or "exactly clear", but the overall impact of these low values was small, indicating that the questionnaire had good content validity.

The theoretical framework for the design of the questionnaire content was Maslow's hierarchy of needs. The participants completed the questionnaire, which assessed the following dimensions of Maslow's hierarchy of needs: (1) Physical needs; (2) Safety needs; (3) Love and belonging needs; (4) Esteem needs; (5) Self-actualization needs; (6) Beyond self-actualization needs; (7) Medical humanities education-relevant needs; and (8) Retentionrelevant needs. The participants were asked to rate their degree of satisfaction of these needs from their jobs on a scale including the options Strongly Agree (SA), Agree (A), Neutral (N), Disagree (D), and Strongly Disagree (SD), which were coded as $5,4,3,2$, and 1 , respectively. We also conducted a pilot study with 30 employed nurses to investigate the reliability of the questionnaire. The Cronbach's alpha $(\alpha)$ coefficient of the overall questionnaire was .94 . The Cronbach's $\alpha$ coefficients of each dimension were as follows: (1) Physical needs, .75; (2) Safety needs, .61; (3) Love and belonging needs, .83; (4) Esteem needs, .79; (5) Self-actualization needs, .83; (6) Beyond self-actualization needs, .8; (7) Medical and humanities education-relevant needs, .94; and (8) Retention-relevant needs, .9. According to the results of the investigation, the scale used in this study had good reliability.

In the present study, the employee satisfaction scale included items rated on a five-point Likert scale. It included 10 items related to the following aspects of employee satisfaction: salary, total weekly working hours, safety in the working environment, mutual assistance, acceptability of constructive advice, and learning resources and opportunities for growth. The scale design was discussed with six nursing experts, and the CVI of each related item was above .8. The participants were asked to rate their degree of satisfaction with their jobs on a scale including the options Strongly Agree (SA), Agree (A), Neutral (N), Disagree (D), and Strongly Disagree (SD), which were coded as 5, 4, 3, 2, and 1, respectively. The 10 -item employee satisfaction scale showed an acceptable level of reliability (Cronbach's $\alpha=$ $.889)$.

\section{Statistical analysis}

In this study, the relationships between the different dimensions of Maslow's hierarchy of needs were determined by using Pearson's correlation test, and the correlation between each dimension and intention to stay was discussed. We also performed simple and multiple regression analyses to investigate the impact of the dimensions of Maslow's hierarchy of needs on the retention of nursing staff in a faith-based hospital in Taiwan.

Pearson correlations were used to assess relationships between all variables in the model. Chi-square tests were used to detect the differences among the different groups for the categorical variables. Linear regression analysis was used to examine the pattern of the relationships among all variables. Logistic regression analyses were used to investigate the association between the nurses' characteristics and intention to stay in the hospital. To assess model fit, we examined the R-square and the $p$ value of the $\mathrm{F}$ statistic $(<0.05)$ as fit indices. SPSS version 24.0 was used to perform descriptive statistical analysis.

\section{Ethical approval}

This study was performed in Taipei Tzu Chi Hospital from May 2017 to April 2018 and was coordinated by the superintendent offices of Taipei Tzu Chi Hospital and Buddhist Tzu Chi Medical Foundation. This study was approved by the Institutional Review Board of Taipei Tzu Chi Hospital (IRB number: 06-X10-026).

\section{Results}

A total of 729 nurses working in different facilities responded to the questionnaire (96.04\% response rate). All analyses were performed as two-sided tests with a 0.05 significance level to explore factors influencing nursing staff retention in their work in relation to different levels of needs.

\section{Cross-analysis of the participants' general characteristics and intention to stay}

The overall analysis demonstrated that only $87.8 \%$ of nurses were willing or very willing to keep working (refer to Table 1). Furthermore, the majority of the participants in this analysis were females (95.6\%). As shown in Table 1, the majority of the participants were under the age of 29 years $(57.9 \%)$, and this age group had the second lowest intention to remain a nurse $(86.7 \%)$. The percentage of participants with a graduate school education was $2.7 \%$; this group was the least likely to report intention to stay (84.2\%). Among these participants, $27.2 \%$ of the nurses had more than 10 years of work 
Table 1 General characteristics of the study participants and difference of intention to stay across different categories of participants' characteristics

\begin{tabular}{|c|c|c|c|c|c|}
\hline & \multirow[t]{2}{*}{$\mathrm{n}$} & \multirow[t]{2}{*}{ percentage } & \multicolumn{2}{|c|}{ Intention to stay (binary) } & \multirow[t]{2}{*}{$P$-value } \\
\hline & & & $n$ & percentage & \\
\hline \multicolumn{6}{|l|}{ Retention } \\
\hline Stay & 636 & 87.8 & & & \\
\hline Leave & 88 & 12.2 & & & \\
\hline \multicolumn{6}{|l|}{ Sex } \\
\hline Male & 31 & 4.4 & 29 & 93.5 & 0.307 \\
\hline Female & 681 & 95.6 & 595 & 87.4 & \\
\hline \multicolumn{6}{|l|}{ Age } \\
\hline Below 29 & 414 & 57.9 & 359 & 86.7 & 0.099 \\
\hline $30 \sim 39$ & 221 & 30.9 & 191 & 86.4 & \\
\hline $40 \sim 49$ & 65 & 9.1 & 63 & 96.9 & \\
\hline Over 50 & 15 & 2.1 & 14 & 93.3 & \\
\hline \multicolumn{6}{|l|}{ Education level } \\
\hline Junior high school & 4 & 0.6 & 4 & 100 & 0.327 \\
\hline Junior college & 295 & 41.2 & 258 & 87.5 & \\
\hline Two-year college & 44 & 6.1 & 43 & 97.7 & \\
\hline Two-year technical college & 163 & 22.8 & 139 & 85.3 & \\
\hline University & 191 & 26.7 & 168 & 88.0 & \\
\hline Graduated school & 19 & 2.7 & 16 & 84.2 & \\
\hline \multicolumn{6}{|l|}{ Religion } \\
\hline None & 375 & 52.5 & 328 & 87.5 & 0.408 \\
\hline Buddhism & 201 & 28.2 & 178 & 88.6 & \\
\hline Taoism & 94 & 13.2 & 83 & 88.3 & \\
\hline Christianity & 21 & 2.9 & 20 & 95.2 & \\
\hline Catholic & 9 & 1.3 & 6 & 66.7 & \\
\hline Other & 14 & 2.0 & 12 & 85.7 & \\
\hline \multicolumn{6}{|l|}{ Seniority of nursing work } \\
\hline Within1 year & 109 & 15.2 & 101 & 92.7 & $0.003^{* *}$ \\
\hline $1 \sim 3$ year & 169 & 23.6 & 152 & 89.9 & \\
\hline $3 \sim 5$ year & 118 & 16.5 & 98 & 83.1 & \\
\hline $5 \sim 10$ year & 125 & 17.5 & 99 & 79.2 & \\
\hline Over 10 year & 195 & 27.2 & 178 & 91.3 & \\
\hline \multicolumn{6}{|l|}{ Seniority of hospital work } \\
\hline Within1 year & 135 & 18.9 & 124 & 91.9 & 0.067 \\
\hline $1 \sim 3$ year & 194 & 27.1 & 172 & 88.7 & \\
\hline $3 \sim 5$ year & 133 & 18.6 & 110 & 82.7 & \\
\hline $5 \sim 10$ year & 141 & 19.7 & 119 & 84.4 & \\
\hline Over 10 year & 112 & 15.7 & 103 & 92.0 & \\
\hline \multicolumn{6}{|c|}{ Time of received medical and human-related education and training in the past six months } \\
\hline None & 90 & 12.6 & 76 & 84.4 & 0.426 \\
\hline $1 \sim 5 \mathrm{~h}$ & 499 & 69.7 & 437 & 87.6 & \\
\hline $6 \sim 10 \mathrm{~h}$ & 102 & 14.2 & 94 & 92.2 & \\
\hline Over $10 \mathrm{~h}$ & 25 & 3.5 & 22 & 88.0 & \\
\hline
\end{tabular}

Note: intention to stay as response scores $\geq 3$ Note: ${ }^{*} p<0.05,{ }^{* *} p<0.01,{ }^{* *} p<0.001$ 
experience related to nursing. Apart from those nurses with less than 1 year of work experience, this group was the most willing to continue working (91.3\%). A total of $12.6 \%$ of the participants had not received medical or human-related education or training during the past 6 months; this group was reported to have the lowest intention to remain (84.4\%).

\section{Bivariate analysis}

The correlations between all the levels of Maslow's hierarchy of needs and intention to stay in this study are displayed in Table 2. The analysis found a positive correlation between each level and intention to stay. Among them, "physiological needs", "safety requirements", "love and subordination needs" and a moderate intention to stay were moderately positively correlated (correlations between 0.30 and 0.50). Furthermore, "selfrealization needs", "beyond self-actualization needs" and "medical humanity education-relevant needs" were strongly positively correlated (correlations greater than 0.60 ), and all correlations reached statistical significance $(p<0.001)$. The results of the study showed that each level of need and medical humanities education were positively related to nurses' intention to stay at their current jobs. This finding was consistent with the research hypothesis. The results also showed that the fulfillment of the needs on Maslow's hierarchy and increased medical humanities education may improve the retention of nursing employees. Retention measures should consider the needs of each dimension of the hierarchy to improve the staff turnover rate.

\section{Multivariate regression}

We constructed a multivariate regression model after controlling for adjusted age, sex, and education level. We found that the dimensions in Maslow's hierarchy of needs had significant positive effects on intention to stay. These results are displayed in Table 3 (also adjusted for the covariates). Furthermore, we found that selfactualization needs, as a risk factor, had the most

Table 2 Correlations for all the levels of needs and intention to stay score

\begin{tabular}{ll}
\hline Levels of Maslow's hierarchy of needs & Intention to stay score \\
\hline Physical needs & $0.559^{* * *}$ \\
Safety needs & $0.533^{* * *}$ \\
Love and belonging needs & $0.393^{* * *}$ \\
Esteem needs & $0.476^{* * *}$ \\
Self-actualization needs & $0.707^{* * *}$ \\
Behind self-actualization needs & $0.728^{* * *}$ \\
Medical humanities education relevant & $0.678^{* * *}$ \\
\hline
\end{tabular}

Note: ${ }^{*} p<0.05,{ }^{* *} p<0.01,{ }^{* * *} p<0.001$ significant association with intention to stay after adjustment for covariates.

\section{Discussion}

In this research, we found a strong correlation between nurses' willingness to remain in their occupations and three dimensions of Maslow's hierarchy of needs: "self-actualization needs", "beyond selfactualization needs" and "medical humanities education-relevant needs". Additionally, regarding retention, nursing staff with less than 1 year or 1-3 years of work experience had substantially greater risk of turnover than senior staff with 5-10 years of work experience.

In the survey, the participants under the age of 29 years represented the majority $(57.9 \%)$ of the participants. Regarding retention, age may be a high-risk factor since it involves a reliance on recruitment budgets and political development [19]. Because not all nurse managers arrange training after recruitment, a lack of training may negatively influence the socialization process of newly hired nurses and contribute to inadequate retention [20]. The nurses' intention to remain in their present occupations was related to multiple demographic and participant characteristics in the results of this research. Notably, younger nurses had lower intention to stay. Because the association between age and intention to leave was not strong, this finding can be explained by the correspondence of age and years of experience. Nurses with more experience are commonly older. The direct connection between years of experience/age and intention to stay is discussed in other studies in the literature [21,22].

Our findings suggest that nurse planners, policy makers, and decision makers should implement targeted retention programs designed to retain newly graduated nurses and inexperienced nurses [23]. The present study findings further indicated that nurses with less than 1 year of work experience were approximately four times as likely to indicate intention to stay in their current jobs than their counterparts with $5 \sim 10$ years of experience in nursing (Table 4). Such findings are also in accordance with previously reported studies in the literature [24]. Sociocultural factors associated with the role of experienced employees in society may also play a role in enhancing nurse retention [25]. Older nurses generally also display higher levels of job commitment [26].

The present study, which drew on Maslow's hierarchy of needs, revealed that influencing factors of nurse retention in Taiwan are related to nurses' professional qualifications. This information allows administrators and medical practitioners to make informed decisions regarding nursing retention. Many medical institutions seem to follow a standard strategy during the 
Table 3 The relationship between Maslow's hierarchy of needs and intention to stay score

\begin{tabular}{|c|c|c|c|c|}
\hline \multirow[t]{2}{*}{ Variables } & \multicolumn{2}{|c|}{ Intention to stay score } & \multicolumn{2}{|c|}{ Intention to stay (adjusted) } \\
\hline & Estimate (SE) & $P$-value & Estimate (SE) & $P$-value \\
\hline Physical needs & $.539(.030)$ & $<0.001^{* * *}$ & $.543(.030)$ & $<0.001^{* * *}$ \\
\hline Safety needs & $.645(.038)$ & $<0.001^{* * *}$ & $.660(.038)$ & $<0.001^{* * *}$ \\
\hline Love and belonging needs & $.530(.046)$ & $<0.001^{* * *}$ & $.556(.046)$ & $<0.001^{* * *}$ \\
\hline Esteem needs & $.590(.041)$ & $<0.001^{* * *}$ & $.598(.041)$ & $<0.001^{* * *}$ \\
\hline Self-actualization needs & $.798(.030)$ & $<0.001^{* * *}$ & $.800(.030)$ & $<0.001^{* * *}$ \\
\hline Behind self-actualization needs & $.715(.025)$ & $<0.001^{* * *}$ & $.719(.026)$ & $<0.001^{* * *}$ \\
\hline Medical humanities education relevant & $.603(.024)$ & $<0.001^{* * *}$ & $.599(.025)$ & $<0.001^{* * *}$ \\
\hline
\end{tabular}

Adjusted age, sex, education level in regression model

Note: ${ }^{*} p<0.05,{ }^{* *} p<0.01,{ }^{* * *} p<0.001$

recruitment period [27], but not all institutions conduct job analysis before starting recruitment. This may be because most interviewing managers are not involved in regular budgeting plans, which can support effective analysis of the main weaknesses of nursing staff.

Within Maslow's hierarchy of needs, physiological needs, safety needs, love and belonging needs (social needs) are also collectively called "deficiency needs." For nursing staff, basic needs such as physiological and safety needs are not met, which may ultimately lead to the loss of nursing staff. The results of this study showed that the participants' satisfaction of their physiological needs was significantly lower than their satisfaction of other needs. This finding demonstrated that the satisfaction of hospital nursing staff with their "working time" and "salary structure" was lower than their satisfaction with other areas. Even with the adjustment of salary structure in hospitals and improvements in the work process, salary and working hours are still important issues for nurses in the workplace.

Salary may not be the primary reason for leaving. A sense of achievement from work, positive relationships

Table 4 Logistic regression of intention to stay (binary)

\begin{tabular}{llll}
\hline Seniority of nursing work & OR & $\mathbf{9 5 \% ~ C l}$ & $\boldsymbol{P}$-value \\
\hline Within1 year & 3.316 & $(1.491,8.158)$ & $0.005^{* *}$ \\
1 3 years & 2.348 & $(1.221,4.622)$ & $0.011^{*}$ \\
3 5 years & 1.287 & $(0.676,2.479)$ & 0.444 \\
Over 10 years & 2.750 & $(1.434,5.399)$ & $0.003^{* *}$ \\
Model adjusted age and sex & & & \\
$\quad$ Within1 year & 4.511 & $(1.818,12.069)$ & $0.002^{* *}$ \\
1 3 years & 3.248 & $(1.500,7.102)$ & $0.003^{* *}$ \\
3 5 years & 1.698 & $(0.820,3.554)$ & 0.156 \\
$\quad$ Over 10 years & 1.566 & $(0.730,3.406)$ & 0.250 \\
\hline
\end{tabular}

Note: reference is $5 \sim 10$ year of seniority of nursing work

Note: intention to stay as response scores $\geq 3$

Note: ${ }^{*} p<0.05,{ }^{* *} p<0.01,{ }^{* * *} p<0.001$ with colleagues, and an ethical culture are important factors contributing to retention [28, 29]. The satisfaction of love and belonging needs (social needs) was reported to be highest across all dimensions. Clearly, hospital employees work through "unit cooperation" and "cooperation with other teams."

With regard to Maslow's high-level needs, esteem needs and self-fulfillment needs are known as advanced "growth needs," and Maslow later added a spiritual need, that is, "beyond self-fulfillment needs." If people's needs are not being satisfied, this will determine their intention to stay. Although there was no significant difference between the groups included in the analysis of medical and human-related education and training hours in the past 6 months, the regression coefficient in the regression model was significant. The promotion of human activities in hospitals should not take a long time.

According to Maslow's theory, people are motivated by a hierarchy of needs. Therefore, when a job meets all levels of people's needs, employee satisfaction will increase accordingly, and willingness to stay at one's current job will follow. Feedback from nursing staff regarding clinical work indicates that the work meets their basic needs (i.e., physiological needs, safety needs, and love and belonging needs), further satisfying self-esteem and self-actualization needs, and even high-level needs for spiritual satisfaction. After having their various needs met, nursing staff will be less likely to resign from their current positions. Health coverage organizations should be able to provide a variety of resources to meet the needs of their nursing staff at all levels in the medical workplace and to attract new nursing staff to maintain clinical operations in hospitals and clinics. Based on the theory of Maslow's hierarchy of needs, this study explored the needs of nursing staff and the relationship between each level of needs and turnover rate. Moreover, a hospital's education and training in medicine and the humanities also affects the clinical practice of nursing staff and their intention to stay. 


\section{Limitations}

The data used in this study were limited to the available data from a faith-based hospital. The present study was conducted at one specific time, not as longitudinal research. In addition, the nurse employees responded to a self-report questionnaire. Data on the professional characteristics of the nurses in the study (shift work, type of contract, nurse rate, and so forth) were not collected in this study. The potential biases of the method was minimized by the substantial sample size and high response rate $(96.04 \%)$.

\section{Conclusion}

We believe that to increase the retention of nursing staff, several strategies could be pursued, including providing a regular day shift system, providing strong basic education and training, cultivating a working environment that values lifelong learning, tailoring a promotion path, strengthening the communication skills of clinical instructors and head nurses, and funding further research investigating ways to improve the retention of nursing staff. Regarding medical humanities education, to make nursing staff more willing to accept the curriculum, we recommend requiring training courses that can be completed during public leave in the curriculum. In addition, it is advisable to tailor different educational programs to different groups (e.g., nurses with 3-5 years of work experience and those with 5-10 years of work experience in the case study hospital) to enhance the effectiveness of medical humanities education.

\section{Supplementary Information}

The online version contains supplementary material available at https://doi. org/10.1186/s12912-021-00558-7.

Additional file 1. English version of the developed questionnaire.

\section{Acknowledgements}

We would like to thank the Department of Nursing, Taipei Tzu Chi Hospital for their support.

\section{Authors' contributions}

LHC and TTS proposed the research idea, performed the analysis, wrote the results and discussion, and contributed to the literature review. CFW supported the literature review. CFW, ANT, RWL, LYY, CMH, WHP, and CYC provided clinical suggestions and helped revise the manuscript. IST supported data analysis, revised manuscript, and prepared the manuscript for submission. All authors read and approved the final manuscript.

\section{Funding}

This research was sponsored by National Taiwan University (grant number NTU-G090049) and partly funded by Taipei Tzu Chi Hospital (grant number TCRD-TPE-109-39 (1/2)).

\section{Availability of data and materials}

Datasets used in the analysis are available from the corresponding author on reasonable request.

\section{Declarations}

\section{Ethics approval and consent to participate}

This study was approved by the Institutional Review Board of Taipei Tzu Chi Hospital, Buddhist Tzu Chi Medical Foundation, and New Taipei City, Taiwan (IRB number: 06-X10-026). Written informed consent was obtained from all participants and be kept strictly confidential.

Consent for publication

Not applicable.

\section{Competing interests}

The authors declare no competing interests with any organization having a direct or indirect financial interest in the subject matter discussed in the manuscript.

\section{Author details}

${ }^{1}$ Superintendent Office, Taipei Tzu Chi Hospital, Buddhist Tzu Chi Medical Foundation, New Taipei City, Taiwan. ${ }^{2}$ Department of Nursing, Taipei Tzu Chi Hospital, Buddhist Tzu Chi Medical Foundation, New Taipei City, Taiwan. ${ }^{3}$ Department of Research, Taipei Tzu Chi Hospital, Buddhist Tzu Chi Medical Foundation, New Taipei City, Taiwan. ${ }^{4}$ Department of Planning and Management, Taipei Tzu Chi Hospital, Buddhist Tzu Chi Medical Foundation, New Taipei City, Taiwan. ${ }^{5}$ Division of Public Communication, Taipei Tzu Chi Hospital, Buddhist Tzu Chi Medical Foundation, New Taipei City, Taiwan. ${ }^{6}$ Graduate Institute of Public Affairs, College of Social Sciences, National Taiwan University, No. 1, Sec. 4, Roosevelt Road, Taipei 10617, Taiwan (Republic of China).

Received: 17 July 2020 Accepted: 1 March 2021

Published online: 12 March 2021

\section{References}

1. Bordignon M, Monteiro MI. Predictors of nursing workers' intention to leave the work unit, health institution and profession. Rev Lat Am Enfermagem. 2019:27:e3219.

2. Hurst K. Primary and community care workforce planning and development. J Adv Nurs. 2006;55(6):757-69.

3. Anand S, Barnighausen T. Human resources and health outcomes: crosscountry econometric study. Lancet. 2004;364(9445):1603-9.

4. Hongoro C, McPake B. How to bridge the gap in human resources for health. Lancet. 2004;364(9443):1451-6.

5. Storey C, Ford J, Cheater F, Hurst K, Leese B. Nurses working in primary and community care settings in England: problems and challenges in identifying numbers. J Nurs Manag. 2007;15(8):847-52.

6. Dubois CA, McKee M, Nolte E. In: Dubois CA, McKee M, Nolte E, editors. Analysing trends, opportunities and challenges In Human resources for health in Europe. Berkshire: Open University Press; 2006. p. 15-40.

7. Ross SJ, Polsky D, Sochalski J. Nursing shortages and international nurse migration. Int Nurs Rev. 2005;52(4):253-62.

8. Buerhaus PI, Auerbach DI, Staiger DO. The recent surge in nurse employment: causes and implications. Health Aff (Millwood). 2009;28(4): w657-68.

9. El-Jardali F, Jamal D, Abdallah A, Kassak K. Human resources for health planning and management in the eastern Mediterranean region: facts, gaps and forward thinking for research and policy. Hum Resour Health. 2007;5:9.

10. Aiken LH, Clarke SP, Sloane DM, Sochalski J, Silber JH. Hospital nurse staffing and patient mortality, nurse burnout, and job dissatisfaction. JAMA. 2002; 288(16):1987-93.

11. Lin CF, Huang Cl, KAO CC, Lu MS. The nursing shortage and nursing retention strategies in Taiwan. J Nurs. 2013;60(3):88-93.

12. Taiwan Union of Nurses Association (TUNA). Nursing Manpower Flow Survey Project, 2014. Available from http://www.nurse.org.tw/DataSearch/ Project.aspx

13. Dussault G, Dubois CA. Human resources for health policies: a critical component in health policies. Hum Resour Health. 2003;1(1):1.

14. Jennings BM. Work stress and burnout among nurses: role of the work environment and working conditions; 2008.

15. Nowrouzi B, Lightfoot N, Larivière M, Carter L, Rukholm E, Schinke R, Belanger-Gardner D. Occupational stress management and burnout 
interventions in nursing and their implications for healthy work environments: a literature review. Workplace Health Saf. 2015;63(7):308-15.

16. Chiu YL, Chung RG, Wu CS, Ho CH. The effects of job demands, control, and social support on hospital clinical nurses' intention to turn over. Appl Nurs Res. 2009;22(4):258-63.

17. Raziqa A, Maulabakhsh R. Impact of working environment on job satisfaction. Procedia Econ Finance. 2015;23:717-25.

18. Clark CS. Watson's human caring theory: pertinent transpersonal and humanities concepts for educators. Humanities. 2016;5:21.

19. Green C. New nursing faculty and incivility: applying mindfulness-based strategies. Holist Nurs Pract. 2018;32(1):4-7.

20. Alameddine M, Yassoub R, Mourad Y, Khodr H. Stakeholders' perspectives on strategies for the recruitment and retention of primary health care employees in Qatar: a qualitative approach. Inquiry. 2017;54: 46958017724943. https://doi.org/10.1177/0046958017724943.

21. Marcum EH, West RD. Structured orientation for new graduates: a retention strategy. J Nurses Staff Dev. 2004;20:118-24. https://doi.org/10.1097/0012464 5-200405000-00003.

22. MacLeod MLP, Stewart NJ, Kulig JC, Anguish P, Andrews ME, Banner D, Garraway L, Hanlon N, Karunanayake C, Kilpatrick K, Koren I, Kosteniuk J, Martin-Misener R, Mix N, Moffitt P, Olynick J, Penz K, Sluggett L, Van Pelt L, Wilson $\mathrm{E}$, Zimmer L. Nurses who work in rural and remote communities in Canada: a national survey. Hum Resour Health. 2017;15(1):34.

23. Blaauw D, Erasmus E: Nurses' attitudes towards working and living in rural areas: initial findings from the CREHS cohort study in South Africa; 2009. Consortium for Research on Equitable Health Systems Research Update. Available on: http://www.crehs.Ishtm.ac.uk/downloads/publications/SA_ cohort.pdf.

24. Smith S, Sim J, Halcomb E. Nurses' experiences of working in rural hospitals: an integrative review. J Nurs Manag. 2019;27(3):482-90.

25. Cosgrave C, Maple M, Hussain R. An explanation of turnover intention among early-career nursing and allied health professionals working in rural and remote Australia - findings from a grounded theory study. Rural Remote Health. 2018;18(3):4511.

26. Jamali D, Sidani Y, Safeieddine A. Constraints facing working women in Lebanon: an insider view. Women Manage Rev. 2005;20(8):581.

27. Unanue W, Gómez ME, Cortez D, Oyanedel JC, Mendiburo-Seguel A. Revisiting the link between job satisfaction and life satisfaction: the role of basic psychological needs. Front Psychol. 2017:8:680.

28. Seren Intepeler S, Esrefgil G, Yilmazmis F, Bengu N, Gunes Dinc N, lleri S, Ataman Z, Dirik HF. Role of job satisfaction and work environment on the organizational commitment of nurses: a cross-sectional study. Contemp Nurse. 2019;55(4-5):380-90.

29. Cohen JH, Foglia MB, Kwong K, Pearlman R, Fox E. How do healthcare employees rate the ethics of their organization? An analysis based on VA IntegratedEthics@ staff survey data. J Healthc Manag. 2015;60(3):169-84.

\section{Publisher's Note}

Springer Nature remains neutral with regard to jurisdictional claims in published maps and institutional affiliations.

Ready to submit your research? Choose BMC and benefit from:

- fast, convenient online submission

- thorough peer review by experienced researchers in your field

- rapid publication on acceptance

- support for research data, including large and complex data types

- gold Open Access which fosters wider collaboration and increased citations

- maximum visibility for your research: over $100 \mathrm{M}$ website views per year

At BMC, research is always in progress.

Learn more biomedcentral.com/submissions 